\title{
Conjuros y ritos mágicos sobre la dentición infantil
}

\author{
A Isabel, Ascensión y Pilar
}

En el Vocabulario de refranes $y$ frases proverbiales de Gonzalo Correas, fechado en Salamanca en 1627, aparece una curiosa formulilla infantil que lleva la siguiente explicación: "Dizen esto los muchachos arroxando el diente ke mudan sobre un texado, i akomódase a otras kosas ke truekan por mexores":

\section{Milano, toma este diente}

i dame otro sano '.

Tal costumbre y su formulilla asociada nos resultarian muy enigmáticas si no fuera porque en la tradición de muchos lugares de dentro y fuera de la Península se conservan bajo apariencias muy parecidas ritos y rimas similares que pueden aclararnos bastante su sentido. En Chile se conserva un conjuro idéntico al documentado por Correas en el siglo XVII. Lo dicen los niños arrojando el diente que se les cae a un tejado, para pedir que el nuevo les salga fuerte:

$$
\begin{aligned}
& \text { Milano, toma este diente } \\
& \text { y dame otro sano }{ }^{2} \text {. }
\end{aligned}
$$

En Portugal se conoce otro parecido, ya que, aunque no cita al milano, sí nombra al atrigueirâo o nome de uma conhecida ave dos campos e dos matos

\section{Trigueirão, trigueirão, toma lá mẽ dente põdre, dá cá o mẽ são ${ }^{3}$.}

1 CORREAS, Vocabulario, ed. L. Combet (Burdeos, 1967), p. 556.

2 Oreste PLATH, Folklore médico chileno (Santiago, 1981), p. 290.

3 José LeTtE DE VASCONCELLos, Opusculos vol. V Etnologia (parte 1) (Lisboa, 1938), pp. $604-605$. 
Pero lo más normal en Portugal, y en las demás tradiciones que iremos conociendo, es hallar fórmulas que aludan sencillamente al acto de arrojar el diente al tejado:

Telhado, telhado, toma lá o meu dente põdre, deita cá o tẽ doirado ${ }^{4}$.

Alguna fórmula portuguesa alude también a San Juan como destinatario del diente:

Em louvor de S. João

toma lá o meu dente podre, dá-me cá um sãos.

También en España son aún muy corrientes este tipo de fórmulas y ritos. En Motril (Granada) se ha conservado hasta hoy la costumbre de arrojar el diente al tejado y pronunciar el siguiente conjuro:

\section{Tejaico, tejaíco,}

toma este dientecico

y dame otro más bonico ${ }^{6}$.

En otro pueblo granadino, Zagra, y además en Fuenteovejuna (Córdoba) y en Miajadas (Cáceres), también se tenía la misma costumbre de arrojar el diente al tejado, al tiempo que se recitaba esta fórmula, idéntica en los tres pueblos:

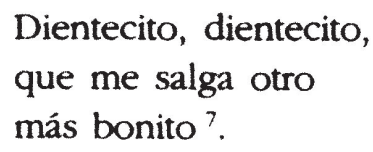

4 LeTte de VASCONCELlos, Opusculos vol. V, p. 604.

' LEITE DE VASCONCELLOS, Tradiçôes populares de Portugal, ed. M. Viegas Guerreiro (2." ed. Vila da Maia, 1986), p. 237. Ver otras muchas fórmulas de este tipo en pp. 236237. Fórmulas que citan a San Juan fueron editadas también en Opusculos vol V, p. 604.

- Versión recitada por Miguel Noguera (Motril, 1968), entrevistado en Granada el 2510-1991 y luego en Sevilla el 26-11-1991, en una encuesta realizada junto con Angel Berenguer.

7 Las tres versiones idénticas de este mismo conjuro me fueron recitadas por María Cervera, nacida en Zagra en 1928 y entrevistada en Vallecas (Madrid) el 14-12-1991; Ascensión Cáceres, nacida en Fuenteovejuna en 1943 y entrevistada en Madrid el 23-11992; y Pilar Rosa, de 56 años, nacida en Miajadas y entrevistada en la misma fecha y lugar que la informante anterior. 
En Guijo de Santa Bárbara (Cáceres) se solía también arrojar el diente al tejado, al tiempo que se pronunciaba un conjuro parecido al anterior:

Diente, dientito, que me salga otro más bonito ${ }^{8}$.

En Villamuñio (León), se usaba el mismo rito, al que acompañaba la siguiente fórmula:

$$
\begin{aligned}
& \text { Dientillo, dientillo, } \\
& \text { te tiro al tejadillo } \\
& \text { para que me salga } \\
& \text { otro más nuevillo?. }
\end{aligned}
$$

Esta es la fórmula que se pronunciaba en Huidobro (Burgos):

$$
\begin{aligned}
& \text { Dientecillo, dientecillo, } \\
& \text { te tiro al tejadillo } \\
& \text { para que me salga otro } \\
& \text { más nuevecillo }{ }^{10} \text {. }
\end{aligned}
$$

En Hoyocasero (Ávila) se tenía también la costumbre de dar la espalda a un tejado o al fondo del hogar y lanzarle el diente para que lo recogiese un angelitom, al tiempo que se decía:

$$
\begin{aligned}
& \text { Dientito, dientito, } \\
& \text { aquí te tiro } \\
& \text { para que me salga otro } \\
& \text { más bonito "1. }
\end{aligned}
$$

En otro pueblo de Ávila, Diego Álvaro, se sigue la misma costumbre, para lo cual conservan también esta fórmula:

Este dientito

$$
\text { lo tiro al tejadito }
$$

\footnotetext{
8 Versión grabada a Isabel Vasco, nacida en 1940 y entrevistada en Vallecas (Madrid) el 12-7-1991.

9 Información facilitada por Vicenta Caballero, de 76 años, y Luciana Prieto, de 71 , en encuesta realizada en Villamuño junto con Marta Nistal y César Palacios, el 26-1-1992.

10 Versión recogida a Sara Andrés, de unos 45 años, entrevistada en Villamuñio (León) el 21-3-1992, en encuesta realizada junto a Margit Frenk, Marta Nistal y César Palacios.

11 Versión recitada por Ana Blázquez, de unos 60 años, y recogida en Hoyocasero por Susana Weich-Shahak y por mí el 3-10-1991.
} 
para que me salga otro

más bonito ${ }^{12}$.

En Mecerreyes (Burgos), lo que se pronunciaba era:

Tejadito nuevo,

toma este diente

y dame uno nuevo ${ }^{13}$.

En Quero (Toledo), se hacía la misma operación, pero pronunciando la siguiente fórmula en el momento de arrojar el diente al tejado:

Ratoncito, ratoncito, que me salga otro más bonito ${ }^{14}$.

En El Rincón de la Victoria (Málaga) se tiraba el diente al tejado, al mismo tiempo que se invocaba a San Onofre, cuya imagen, desdentada y vestida de hiedra, es muy venerada en ese pueblo y en otras zonas de Málaga. Normalmente el diente solía resbalar por el tejado, por lo que era común lanzarlo varias veces, teniendo mucho cuidado de no perderlo para que no saliese un diente de burro:

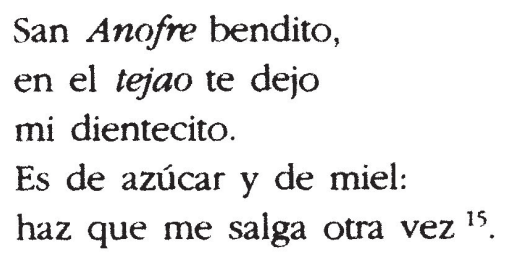

12 Versión recitada por María José Hernández, nacida en 1955 y entrevistada en Vallecas (Madrid) el 27-2-1992.

13 El informante Salvador Alonso, de 29 años, fue entrevistado en Madrid el 8-11-1992.

1. Versión comunicada por Petra Ruiz, de 62 años, entrevistada en Madrid el 15-2-1992.

15 Información facilitada por Encarnación Rando, nacida en El Rincón de la Victoria hace 57 años, y entrevistada en Vallecas (Madrid) el 7-11-1991. San Onofre era el abogado de los dientes y las muelas, y muy invocado en otros trances difíciles, como el de la protección de los hijos que se iban al servicio militar. Su imagen se conservaba en la sala de entrada de la casa particular de una vecina, pero a ella acudía mucha gente para hacerle promesas y entregarle unas hojas de hiedra (nunca más de tres) y una rosca de pan. Después de que el diente nuevo hiciese su aparición, todavía decía el niño otro conjuro para pedir - detalle importante- el pan que entonces se había de masticar:

San Anofre bendito que al monte subiste, de vellos y yedra 
Por lo que respecta a la tradición sefardí de Oriente, cuenta Michel Molho la siguiente costumbre de Salónica: "de siete a ocho años el niño pierde los dientes de leche. Todavía es inocente y crédulo. Cada vez que se le cae un diente, se apresura a lanzarlo sobre un tejado. Hélo aquí pronunciando con convicción la siguiente formulilla:

Tejadico, mi tejadico, toma el viejecico, dame un muevecico.

Es curioso notar que, a muchos miles de kilómetros de distancia, en los Cárpatos, tanto como en el fondo de Rusia y en las orillas del Danubio, el pequeño aškenazí obra absolutamente de la misma manera, con la sola diferencia de que en lugar de tirar su diente a las tejas, lo deja caer en un agujero de ratones. Esto le traerá buena suerte, según él cree firmemente" ${ }^{16}$.

La costumbre y la fórmula que se le asocia no son privativas de las tradiciones que acabamos de conocer. Se conservan, con innumerables variantes, en muchos otros lugares de España e Hispanoamérica ${ }^{17}$, así como en

tu cuerpo cubriste,

el rey de los cielos

tres voces te dió:

los dientes y el pan

nos mandó,

dánoslos por caridad,

que te lo pedimos

con mucha necesidad.

16 Molho, Usos y costumbres de los sefardies de Salónica (Madrid-Barcelona, 1950), p. 90.

17 Ver por ejemplo, Constantino CABAL, "Mitología ibérica", Folklone y costumbres de España (Barcelona, 1931-1934), I, pp. 165-288: p. 284; Gerardo LÓPEZ DE GUEREÑU, .La vida infantil en la montaña alavesa", RDTP, XVI (1960), pp. 139-179: p. 142; Julio CARO BAROJA, Apuntes murcianos (De un diario de viajes por España, 1950) (Murcia, 1984), p. 103; José María DOMínguez MORENo, Cultos a la fertilidad en Extremadura (Mérida, 1987), pp. 5-6; Prácticas y creencias supersticiosas en la provincia de Salamanca, J. F. BLANCO, coord., Archivo de Tradiciones Salmantinas, 2 (Salamanca, 1987), p. 25; Juan Francisco BlaNCO, .Lenguaje y magia., L. Díaz Viana (ed.), Aproximación antropológica a Castilla y León (Barcelona, 1988), pp. 259-292: p. 284; Domingo GarCia Barbuzano, Prácticas y creencias de una santiguadora canaria $\left(6 .^{2}\right.$ ed., Tenerife, 1990), p. 72; Angel CARRIL, Etnomedicina popular: acercamiento a la terapéutica popular (Valladolid, 1991), pp. 1617. Ver además Enrique CASAS GASPAR, Costumbres españolas de nacimiento, noviazgo, casamiento y muerte (Madrid, 1947), p. 83; y José Manuel GOMEZ-TABANERA, El curso de la vida humana en el folklore español, El folklore español (Madrid, 1968), pp. 67-128: 
Portugal ${ }^{18}$ y Marruecos ${ }^{19}$. En nuestro país existe, además de la costumbre de tirar el diente al tejado, la de arrojarlo al horno o al fuego del hogar ${ }^{20}$, al cementerio $^{21}$ o a alguna ermita ${ }^{22}$; el de introducirlo en algún resquicio de

p. 96. Para versiones hispanoamericanas, ver PLATH, Folklore médico chileno (Santiago, 1981), pp. 288-290, donde hay o se citan tres versiones venezolanas, dos brasileñas, una argentina y una chilena; y también Paulo de CARVAlHo-NeTO, Folklore poético (Quito, 1966), p. 186. Ver además, para versiones argentinas, de Juan DRAGHI LUCERO, Cancionero popular cuyano (Mendoza, 1938), p. 317; y Julio ARAMBURU, El Folklore de los niños (2. ed., Buenos Aires, 1944), p. 150; chilenas en Aurelio M. ESPINOSA, *Miscellaneous materials from the Pueblo indians of New Mexico,, Philological Quarterly, XXI (1942), pp. 121-127: p. 127, y PLATH, Folklore chileno (Santiago, 1946), p. 38; brasileñas en Sebastián ALMEIDA OlIVERA, "Supersticiones y creencias del Sertanejo", F. Coluccio (ed.), Folklore de las Américas (Buenos Aires, 1949), pp. 87-90: p. 88; venezolanas en R. OLIVARES FIGUEROA, Folklore venezolano, I (Caracas, 1948), p. 103; colombianas en José Joaquín MONTES GIRALDO, Medicina popular en Colombia: vegetales $y$ otras sustancias usadas como remedios (Bogotá, 1981), p. 40; dominicanas en Edna GARRIDO DE BOGGS, Folklore infantil de Santo Domingo (Madrid, 1955), p. 643; y nuevomejicanas en Aurelio M. EsPINOSA, •Romancero nuevomejicano", Rerue Hispanique, XXXIII (1915), pp. 446-560, núm. 130, y •Folklore infantil de Nuevo Méjico", RDTP, X (1954), pp. 499-547: núm. 38.

18 Además de las versiones citadas, puede verse otra versión portuguesa en Rodney GALloP, Portugal: a Book of Folk-Ways (reed. Cambridge, 1961), p. 88.

19 Ver Mohammed IBN AzZUZ AKIM, Diccionario de supersticiones y mitos marroquies (Madrid, 1958), p. 23, donde se afirma que, además de tirar el diente infantil a la azotea, también existe la costumbre de arrojarlo al fondo de un pozo o de enterrarlo. Entre los judíos sefardies de Marruecos existía también la costumbre de mezclar sal con el diente y echarlo a un cañito" para que los demás dientes saliesen mejores, según informes proporcionados por Alegría Anijar (Arcila, 1933), entrevistada en Yafo (Israel) por Gladys Pimienta en 1981 (información proporcionada por el Proyecto Folklor de la Radiodifusión israelí, y que agradezco a su director, Moshé Shaul). Sobre la mezcla del diente con sal -repelente de malos espíritus-, ver también Iona OPIE y Moira TATEM, A Dictionary of Superstitions (Oxford-Nueva York, 1992), p. 393.

20 Sobre la costumbre y los conjuros para el lanzamiento del diente al homo o al hogar, ver Ramón CANGAS FONTERIZ, "La medicina popular en Ibias", Boletín del Instituto de Estudios Asturianos, XIII (1959), pp. 441-448, y XIV (1960), pp. 292-298: pp. 296-298; Luciano CASTANOON, Supenticiones y creencias de Asturias (reed. Gijón, 1986), pp. 43-44; y MOnique VAN DER REIJEN, Costumbnes, tradiciones $y$ dialecto en Asturias (tesis doctoral: Amberes, 1986), pp. 77-79 (cfr. además la Gran Enciclopedia Asturiana, Gijón, 1970, s.v., diente). Para José M." Rodríguez MORENo, que analiza la misma costumbre en Extremadura, el método es el mismo que el del lanzamiento al tejado y también la intención. Al ser el fuego el lugar sagrado de la casa, morada de los antepasados, allí se arrojan los dientes como sacrificio a los manes, quienes a su vez harán la nueva donación: (cfr. Cultos a la fertilidad, p. 6). El mismo rito conservado entre los vascos ha recibido parecida explicación en A. ARRINDA, Religión primitiva de los vascos (Bilbao, 1985), p. 271; también se practica en Portugal, según Zófimo Consiglier PEdroso, sSuperstições populares (vária), Contribuçōes para uma Mitologia Popular Portuguesa e Outros Escritos 
paredes, puertas o ventanas ${ }^{23}$; el de machacarlo ${ }^{24}$, el de engastarlo en un collar o sortija ${ }^{25}$ o, más modernamente, el de dejarlo bajo la almohada del niño para que durante el sueño venga el "ratón Pérez" a cambiarlo por un regalo ${ }^{26}$. Quienes practican semejantes ritos suelen justificarlos diciendo que

Etnográficos (reed. Lisboa, 1988), pp. 201-213: p. 494; igualmente en Francia se conocía este rito, ya que Ed. TOUBIN, superstition relative aux dents", Mélusine, I (1878), col. 365 (reproducido en José PÉREZ BALLESTEROS, supersticiones", Biblioteca de las Tradiciones Populares Españolas, IV, Sevilla, 1884, pp. 86-90: p. 89), da la siguiente versión francesa del conjuro:

Tiens, feu, voilá ma dent, rends-la moi dans un mois, blanche comme l'argent.

Cfr. además Arnold VAN GENNEP, Manuel de Folklore Français Contemporaine (reed. Paris, 1977), I, p. 151. Para correspondencias inglesas, ver OPIE y TATEM, A Dictionary of Superstitions, pp. 393-394:

Fire, fire, burn a bone,

God send me another tooth again:

a straight one, a white one,

in the same place.

21 Según me informa Emelina Álvarez, de LJamazares (León), entrevistada en Getafe (Madrid), el 11-6-1991. Poseo informaciones sobre la misma práctica en el pueblo asturiano de Santa Marina de Piedramuelle (vid. nota 32 infra). Ver además de José Luis GARCIA ARIAS, "Aportaciones al folklore asturiano", BIDEA, XXIX (1975), pp. 651-701: p. 665.

22 En el pueblo leonés de Casares de Arbas me informó Nieves Rodriguez Cañón, nacida en 1937 y entrevistada el 1-10-1991 por María José Sanz y por mí, de que el niño subía su diente a la ermita de la Virgen de Arbas y lo metía por un ventanuco al interior del templo, mientras decía:
Muro, murato,
toma este diente quebrado
y dame otro sano.

23 Vid. Blanco (ed.), Prácticas y creencias, p. 25 y CARRIL, Etnomedicina, p. 17. En Fran-cia se tiene también la costumbre de esconder el diente en algún agujero de las paredes de la casa, al tiempo que se invoca a un ratón equivalente a nuestro Ratón Pérez (vid. nota 26 infra):

Petite souris,

je t'apporte une de mes dents,

donne-m'en une autre.

Cfr. Paul Sťbluot, Le Folklore de France: La Faune (reed. Paris, 1984), p. 65.

24 Ver Blanco, Prácticas y creencias, p. 25.

25 Ver GOMEZ-TABANERA, -El curso de la vida humana", p. 96; y CARRIL, Etnomedicina, p. 17. En muchos lugares de España y de Hispanoamérica se tiene la costumbre de llevar colgado del cuello el primer diente, o de guardarlo como si fuese una joya.

26 Blanco (ed.), Prácticas y creencias supersticiosas, p. 25. La costumbre de entregar. el diente caído a este simpático ratón ha desbancado hoy en casi toda España a los demás 
si el diente es arrojado a la calle y se lo come una gallina ${ }^{27}$, un perro ${ }^{28}$, un gato $^{29}$ o un caballo ${ }^{30}$ no volverá a salir, o saldrá como los del animal que se lo tragó; algunos también creen que si lo encuentra el diablo o los espíritus malignos podrán usarlo con fines de magia negra, perjudicial para el dueño ${ }^{31}$; o que, si se pierde, habrá de volver el alma a buscarlo el día del Juicio Final porque el cuerpo deberá estar completo el día de la Resurrección ${ }^{32}$.

ritos relacionados con la dentición infantil, incluyendo el del lanzamiento a los tejados, cada vez más raros (sustituidos por áticos y terrazas) o más altos e inaccesibles en nuestras ciudades y pueblos. Ya vimos, en una nota anterior, que este célebre Ratoncito Pérez español tiene correspondencias en otras tradiciones, como en la francesa, donde es conocido como "la Petite Sourisn. En Gran Bretaña es el Hada del Diente (the Tooth Fairy) quien deja monedas bajo la almohada del niño al que se le ha caído su diente (OPIE y TATEM, A Dictionary of Superstitions, p. 394).

27 Ver LOPEZ DE GUEREÑU, "La vida infantil", p. 142; AMADES, Folklore de Catalunya, III, p. 81; y Antonio Fraguas Fraguas, "Estudio antropológico de la población", Enciclopedia temática de Galicia: Antropología (Barcelona, 1988), pp. 13-82: p. 45.

28 LOPEZ DE GUEREÑU, "La vida infantiln, p. 142; AMADES, Folklore de Catalunya, III, p. 81; VIOLANT I SimORRA, El Pirineo, p. 277. También en Francia se manifiesta esta creencia (cfr. TOUBIN, "Superstition relative aux dents", col. 365; Robert JALBY, Le Folklore $d u$ Languedoc, Paris, 1971, p. 27; y Pérez Ballesteros, "Supersticiones", p. 89), lo mismo que en Inglaterra (OPIE y TATEM, A Dictionary of Superstitions, p. 393).

29 TOUBIN, "Superstition relative aux dents", col. 365.

30 Información facilitada en Madrid el día 7-8-1991 por Sara Nieto, nacida en 1947 en Ponteareas (Pontevedra). Sobre los peligros de que animales en general encontrasen y comiesen los dientes infantiles, ver Xesús TABOADA CHIVITE, "Cultura material y espiritual", X. R. BARreiro, F. Díaz-Fierros et al.. Los gallegos (2." ed., Madrid, 1984), pp. 149-218: p. 193; y José Lisón Huguet, Algunos aspectos del estudio etnográfico de una comunidad rural del Pirineo aragonés oriental (Zaragoza, 1984), p. 123.

31 Efectivamente, en algunos pueblos se destruía el diente en el fuego o en el mortero para que no pudiese encontrarlo y utilizarlo el diablo, según informes del pueblo de Orellana la Vieja (Badajoz) facilitados por Manuela Sanz, nacida en 1927 y entrevistada el 23-8-90. En otros se enterraba el diente debajo de una "garrabera. para evitar que quien lo encontrara obrase con él algún maleficio (cfr. LISÓN HUGUET, Algunos aspectos, p. 123). En Duesaigües (Barcelona), tiraban los dientes a la boca del diablo que estaba caído y sometido a los pies de la imagen de San Miguel, y que, por tanto, ya no podía utilizarlo con fines maléficos (cfr. AMADEs, Folklore de Catalunya, III, p. 81). Las creencias sobre la posible utilización mágica nociva de los dientes son muy antiguas en España. Se conoce, por ejemplo, un proceso inquisitorial del siglo XVII contra Juana Trujillo, gitana de Cabia la Grande (Granada), que para asegurarse el amor de su amante llevaba una bolsa con cabellos, uñas y un diente de aquél (cfr. a este resecto Juan BLÁzQuez Miguel, Eros y Tánatos: brujeria, bechicería y superstición en España, Toledo, 1989, p. 132).

32 Ver Consolación GONZÁlez CASARRubios y Esperanza SÁNCHEZ MORENo, Folklore toledano: fiestas y creencias (Toledo, 1981), p. 88; LISÓN HUGUET, Algunos aspectos, p. 123; Violant I Simorra, El Pirineo, p. 277; Van Gennep, Manuel de Folklore, I, pp. 151-152; y 
Algunas de las fórmulas y creencias que en ciertas zonas acompañan el lanzamiento del diente al tejado revisten especial interés. Por ejemplo, en el País Vasco se suponía que así se le ofrecía a la diosa Mari, la gran matriarca de la mitología vasca, a la que se invocaba de este modo:

\author{
¡Marijje, Marijje! \\ Etxi au agiñé \\ ta ekau niri barrijje. \\ ¡Marijje, Marije! \\ Toma este diente \\ y dame uno nuevo ${ }^{33}$.
}

\begin{abstract}
Juan RODRÍGUEz PASTOR, "Las supersticiones: su estado actual en Valdecaballeros", Revista de Estudios Extremeños, XIIII (1987), pp. 750-779: p. 776. Mi informante de Fuenteovejuna (vid. nota 7 supra) pensaba que el día del Juicio Final habria que venir a buscar la dentadura desde el otro mundo, y que por eso era mejor que estuviese a salvo sobre el tejado. En el pueblo asturiano de Santa Marina de Piedramuelle, según información recogida en Vallecas (Madrid) el 10-9-1991 a la señora Adelina López, de 60 años, también se creía que los niños debían tirar el diente al cementerio para no tener que volver a buscarlo con una vela el día del Juicio. En Almagro (Ciudad Real), según me informa María José López, de 27 años, entrevistada en Vallecas (Madrid) el 30-3-1992, se guardaban los dientes para que no tuviese que venir el alma, después de muerta, a buscarlos con un candil colgado del ombligo; y en Mogarraz (Salamanca), según informes de Adela Núnez, nacida en 1902 y entrevistada el 8-10-90, se guardaban los dientes en una bolsita y se metían en el ataúd para que el día de la Resurrección, el cuerpo estuviese completo. Sobre parecidas creencias en Gran Bretaña, ver OPIE y TATEM, A Dictionary of Superstitions, p. 394.
\end{abstract}

33 Antón ERKOREKA, Análisis de la medicina popular vasca (Bilbao, 1985), pp. 200202. Conjuros de este mismo tipo o parecido (para acompañar el lanzamiento del diente al tejado o al fuego) se editan en esta misma obra; en Julio CARO BAROJA, La vida rural en Vera de Bidasoa (Madrid, 1944), p. 134; Ignacio María de BARRIOLA, La medicina popular en el País Vasco (San Sebastián, 1952), pp. 88-91: p. 90 (•debe echarse al tejado, por la chimenea, al fuego, invocando al tiempo la protección de la Virgen Maria, de Dios, recurriendo a 'María la del tejado' o al murciélagon); Antón ERKORFKA, “Etnografía de Bermeo II: ritos de pasaje (Investigaciones Etniker-Bizkaia)., Anuario de Eusko-Folklore, XXVII (1977-1978), pp. 169-242: p. 183: A. ARRINDA, Religión primitiva de los vascos (Bilbao, 1985), p. 271; y Ramón VIOLANT I SIMORRA, El Pirineo español: vida, usos, costumbres, creencias y tradiciones de una cultura milenaria que desaparece (reed. Barcelona, 1989), p. 277. Ver también José Miguel de Barandiarán et al., El hombre prebistórico en el País Vasco (Buenos Aires, 1953), p. 182. Sobre la diosa Mari en la mitología vasca, ver BARANDIARÁN, "Mari, o el genio de las montañas", tirada aparte del Homenaje a don Carmelo de Echegaray (San Sebastián, 1923); CARO BAROJA, Sobre la religión primitiva y el calendario del pueblo vasco (San Sebastián, 1984), pp. 61-72; José M. ${ }^{2}$ Satrústegui, Mitos y creencias (Irún, 1987), pp. 110-119; Barandiarán, De etnografía de Navarra (San Sebastián, 1987), pp. 129-135; VIOLANT I SiMORRA, El Pirineo, p. 528; y Barandiarán, Mitología vasca (8. ${ }^{2}$ ed. San Sebastián, 1990), pp. 99-122. 
En Nuevo México recogió Aurelio M. Espinosa algunas interesantes versiones que él suponía de raigambre española pero adaptadas al mundo mítico y a la lengua indígenas: "Cuando un niño de Acoma pierde un diente se dirige un amanecer hacia el Este con una cantidad de trigo y el diente. Extiende el trigo sobre la arena y pone allí el diente. Entonces coloca algunos palos sagrados sobre la arena y pide al sol otro diente. Esto se hace temprano por la mañana. En Isleta un niño que pierde un diente lo arroja al sol y le pide uno nuevon. He aquí los conjuros que utilizan para estas ocasiones:

Tâ sendó, tâ sendó, weê, wâe sambí dimê

(Viejo sol, viejo sol, toma este diente y dame uno nuevo)

An tomena tulena, mamú víe wraya, shoi chemai

(Padre sol, toma este diente y dame uno mejor) ${ }^{34}$.

Pero no es sólo en las culturas de raíz peninsular o hispánica donde se observan ritos de este tipo en relación con la caída de la primera dentición. Sabemos, efectivamente, gracias por ejemplo a los trabajos antropológicos de James G. Frazer, que existe una «relación simpatética que continúa entre el muchacho y sus dientes" documentada entre los aborígenes de Australia, de Nueva Gales y en otros muchos pueblos ${ }^{35}$. Como lección reveladora de la auténtica significación de los ritos en torno a los dientes infantiles en tantas latitudes, nada puede haber más aleccionador que atender al siguiente párrafo del antropólogo británico:

En muchas partes del mundo es costumbre colocar los dientes extraídos en algún lugar donde fácilmente puedan ser hallados por un ratón o una rata, en la esperanza de que por intermedio de la simpatía que sigue existiendo entre el diente y su anterior propietario, sus otros dientes adquieran la firmeza y excelencia de los dientes de estos roedores. Por ejemplo en Alemania es una máxima muy extendida entre las gentes que se debe colocar en el agujero de un roedor el diente extraído. Haciéndolo así con los dientes de leche se evitará que el niño contraiga dolores de dientes; también hay que colocarse ante la chimenea del hogar y arrojar hacia atrás el diente diciendo: "Ratón, déme su diente de hierro; yo le daré el mío de hueso.. Después de esto, sus otros dientes permanecerán sólidos. Muy lejos de Europa, en Raratonga, en el Pacífico, cuando se extraía un diente a una criatura, se solía recitar la siguiente oración:

Gran rata, pequeña rata,

aquí está mi viejo diente;

os ruego me déis uno nuevo.

Después arrojaban el diente sobre las bardas [techado o cobertizo de paja] de la casa, porque las ratas hacían sus nidos en las bardas viejas. La razón asignada para

\footnotetext{
34 ESPINOSA, "Miscellaneous materials, pp. 126 y 127, y núms. 12 y 13.

FRAZER, La rama dorada lversión reducida] (México, 1944), p. 56.
} 
invocar las ratas en estas ocasiones era que para los nativos son dientes de rata los más fuertes que conocían ${ }^{36}$.

Las asombrosas similitudes entre el conjuro que se dice en el Pacífico antes de arrojar el diente sobre el techado de paja ("Gran rata, pequeña rata, / aquí está mi viejo diente; / os ruego me déis uno nuevon) y el que se puede decir en cuaquier pueblo de España, de Hispanoamérica o del Oriente sefardí (por ejemplo, «Tejadito nuevo, / toma este diente viejo / y tráeme otro nuevon), así como la asociación simpática de los ratones y tejados a estos ritos en ámbitos tan diferentes, nos enfrenta a un fenómeno de pervivencia de ancestrales ritos culturales en entornos muy distanciados que nos puede dar idea de la profundidad, muchas veces inadvertida, de nuestra herencia cultural.

En efecto, con escasas diferencias sobre lo que era común en Raratonga, también los tejados y desvanes de España y de otros países han sido, y más en épocas pasadas, lugar propicio para la anidación de los ratones. A eso, a la creencia del contagio simpático de la fortaleza dentaria de esos animales, y al deseo de que objetos tan mágicamente sensibles como los dientes vayan a parar a lugares inaccesibles a contactos impuros ${ }^{37}$, debe obedecer la costum-

36 FRAZER, La rama dorada, pp. 57-58. Debe tenerse en cuenta, además, que la fortaleza dentaria de los ratones era tenida ya por mágica y excepcional entre los antiguos griegos y romanos. Aristóteles, Claudio Eliano, Plinio, Teofrasto y Suida recogen la creencia de que los ratones son capaces de comer hierro, acero y oro, razón por la que, en opinión de algunas de estas autoridades, eran perseguidos por los plateros con el afán de abrirlos y hallar en su interior estos productos. Ver acerca de estas creencias, Claudio Eliano, Historia de los animales: libros I-VIII, ed. J. M. Díaz-Regañón López (Madrid, 1984), V:14, p. 228; y Juan de PINEDA, Diálogos familiares de la Agricultura cristiana, 5 vols. [Biblioteca de Autores Españoles (Madrid, 1963-1964), vol. IV, núm. CLXIX], p. 240. En la Galicia antigua parece que existieron ritos de veneración mágica a los ratones (cfr. Vicente RisCO, "Creencias gallegas: tradiciones referentes a algunos animales", RDTP, III, 1947, pp. 163-188 y 371-400: p. 395). Hay que señalar, además, que en otras culturas tradicionales no sólo era apreciada la fortaleza dentaria de los ratones, sino también su inteligencia, lo que explica, por ejemplo, que en Persia se escondiese la placenta en las madrigueras de ratones para que el niño que naciese con ella saliese inteligente ( $\mathrm{cfr}$. RuFfat, La superstición, p. 183).

37 En Espana, no sólo los dientes, sino también otros objetos mágicamente sensibles como las uñas cortadas o el agua bendita que sobra de las iglesias se lanzan al tejado para evitar que sean pisados o mal utilizados. En Puentegenil (Córdoba), se arrojaban al tejado las uñas de los niños envueltas en un papel, para que no fueran pisadas por nadie y - cosa curiosa - para que el niño saliera buen cantor (información facilitada por la señora Natividad Serrano, nacida en 1921 y entrevistada el 11-8-1991 en Vallecas, Madrid). Costumbres parecidas documentan Alejandro GUICHOT Y SIERRA, Supersticiones populares andaluzas (reed. Sevilla, 1986), p. 125; A. RUFFAT, La superstición a través de los tiempos (Barcelona, 1962), p. 288; PLATH, Folklore médico chileno, p. 254; y RODRIGuez PASTOR, .Las supersticiones", p. 776; más supersticiones sobre la sensibilidad mágica de las uñas se 
bre de arrojar el diente a los ratones del tejado $\longrightarrow$ a otros elementos o lugares mágicos como el fuego, las ermitas, los santos como San Juan en Portugal o San Onofre en Málaga, la diosa Mari en Vascongadas, el "padre solı en Nuevo México o las aves de fuerte pico documentadas por Correas y algunos folcloristas modernos-: restos palpables de formas de vida y de relación con el propio cuerpo y con la naturaleza de carácter mágico que asoman a nuestra época tras una andadura seguramente muy larga desde épocas remotas.

Recordemos, a este respecto, que si Frazer demostró la antigua y universal asociación mágica de dientes, tejados y ratones al documentarla en lugares tan alejados como el Pacífico, también probó el primitivismo de los ritos de ocultación de los dientes a los animales o a las fuerzas malignas al señalar la existencia en otros países europeos y en el África Negra de prácticas no muy diferentes a las que se siguen en España ${ }^{38}$. El difundido uso en nuestro país de amuletos facilitadores de la dentición y asociados en muchos casos

encontrarán en RENÉ BASSET, "Les ongles", Mélusine, II (1884-1885), col. 360; y en "Les ongles des jeunes enfantsn, Mélusine, II (1884-1885), cols. 486-487; en curiosa relación con la creencia de la interrelación entre uñas y voz, y con la de la primera dentición, está la del pueblo catalán de Sant Sadurní d'Anoia, donde los que salían buenos cantantes eran, en opinión del pueblo, los que más pronto y mejor echaban los primeros dientes (cfr. AMADES, Folklore de Cataluña, III: p. 81). El agua bendita que sobraba de la iglesia era arrojada a los tejados, para que nadie la pisase, en el pueblo de Soberado (Cantabria), según me informa Jesús García, de 25 años, entrevistado en Madrid el 14-12-1991.

38 Sobre las precauciones para que el diente no caiga en poder de cualquier animal, leemos en La rama dorada, p. 57, que en Sussex, hace unos cincuenta años, una criada se oponía fuertemente a tirar un diente de leche de una criatura, asegurando que podría ser encontrado por algún animal que lo royera y en ese caso, el diente nuevo sería exactamente como los del animal que mordió el diente de lechem. También en Grecia parece que se toman precauciones para que el diente no sea encontrado por un gato y salga el nuevo como el de este animal (información facilitada por Dimitri Filippis, nacido en Eubea en 1961 y entrevistado en Madrid el 12-12-1991). Sobre las precauciones para que el diente no caiga en poder de las fuerzas del mal, nos informa FrAzER, en La rama dorada, p. 57, de que en el África Negra slos basutos evitan cuidadosamente que los dientes extraídos caigan en las manos de ciertos seres míticos que rondan las sepulturas y que pueden hacer dano a los propietarios de los dientes haciendo magia con ellos.. Téngase en cuenta también que el miedo al diablo es el que hace que en Inglaterra y Marruecos se arroje el diente al tejado (o al fuego, a un pozo, o a un agujero donde se entierra), envuelto en un trapo de lana con un poco de sal, sustancia repelente del diablo en ésa y en muchas culturas (cfr. Azzuz AKIM, Diccionario, p. 23). También en La rama dorada, pp. 284-288, se documentan ritos análogos en relación con las uñas o con el pelo, que igualmente son tratados en muchas culturas con precauciones de tipo mágico. Supersticiones parecidas en relación con el pelo se conservan en Andalucía. Así, GLICHOT y SIERRA, en Supersticiones, p. 125, señala que es muy malo tirar a la calle barañas de pelo, porque pueden cogerlas y hacer mucho daño a la persona dueña del cabelo, echándole a éste una maldición jitana o haciéndole mal de ojo: maldición y mal que pasa del cabello a la persona. 
a los ritos que estamos analizando, vuelven a ser síntoma de su antigüedad, ya que antropólogos como Barandiarán no dudan en considerarlos reminiscencias de prácticas prehistóricas ${ }^{39}$.

Con esto adquirimos una idea suficiente del viejo y extendido marco cultural en que se inscriben las fórmulas orales y las costumbres observadas, dentro y fuera de España en relación con la caída de los dientes infantiles: fórmulas y costumbres que contribuyen a aclaramos el sentido del enigmático dicho apuntado por el maestro Correas en el siglo XVII, y nos permiten profundizar en los códigos universales y complejos en que se enmarca parte de nuestra cultura.

José Manuel Pedrosa

Desde el siglo Xvi hasta hoy, se documentan en Espana fórmulas y ritos de lanzamiento de dientes infantiles a los tejados o de entrega a los ratones. La asociación mágica de dientes, tejados y ratones en ritos que se conservan en todo el mundo contribuye a aclarar su existencia en España.

Since the XVII th century until now, conjurations and rites of throwing children teeth to roofs or giving them to mice are documented in Spain. The magic association of children teeth, roofs and mice in rites conserved all over the world helps to explain its existence in Spain.

39 Ver a este respecto BARANDIARÁN, "Paralelo entre lo prehistórico y lo actual en el País Vasco: investigaciones en Balzola y en Gibijom, Anuario de Eusko-Folklore, XII (1932), pp. 101-120: p. 104; del mismo autor, Fragmentos folklóricos: paletnografia vasca (San Sebastián, 1921), p. 40; y Mitología vasca. p. 44. En realidad, ya PuNIO, en su Historia natural, XXVIII, 7:12, alude al uso como amuleto del primer diente del niño; sobre la pervivencia de esta costumbre en las tribus oceánicas, ver de Emest CRAwleY, The Mystic Rose, revisión de T. BESTERMAN (reed. Londres, 1965), p. 142. Para más noticias sobre el uso como amuleto en toda la Península de bolsitas o collares con dientes de animales (erizo, caballo, serpiente, lobo, conejo, perro, jabalí, cerdo, lagarto, ratón, topo), de pretendidas facultades transmisoras de fortaleza dentaria, ver LeITE DE VAsconcellos, Opusculos, vol. V, p. 562; Rafael SAuLlas, La fascinación en España (brujas, brujerias, amuletos) (Madrid, 1905), p. 73; BARRIOLA, La medicina popular en el País Vasco, pp. 88-91; Sebastián JIMÉNEZ SÁNCHEZ, Mitos y leyendas: prácticas brujeras, maleficios, santiguados y' curanderismo popular en Canarias (Las Palmas, 1955), p. 37; Vicente RisCO, "Apuntes sobre el mal de ojo en Galicia". RDTP, XVII (1961), pp. 66-92: p. 82; CANGAS FONTERIZ, "La medicina popular*, pp. 444-445; Robert JALBY, Sorcellerie et Médicine populaire du Languedoc (Nyons, 1974), p. 165; Francisco Javier y José Angel ZUBIAUR, Estudio etnográfico de San Martín de Unx (Navarra) (Pamplona, 1980), pp. 152153, nota 7; AMADES, Folklore de Catalunya, III, pp. 79-80; PLATH, Folklore médico chileno, pp. 301-303; VIOlant i SimOrRa, El Pirineo, p. 277; Blanco (ed.), Medicina y veterinaria, p. 36; RODRÍGUEZ PASTOR, "Las supersticiones", p. 777; y CARRIL, Etnomedicina, p. 17; sobre parecidas costumbres en Francia, ver SFBLLLT, Le Folklore de France: La Faune, p. 65. Sobre el uso de colmillos de cabra para ahuyentar el mal de ojo, ver de A. Elsa LOPEZ RODRfGUEZ, "La simbología en la medicina popular canaria", RDTP, XIII (1987), pp. 117-140: p. 128. Sobre fuentes antiguas y pervivencias inglesas, ver OPIE y TATEM, A Dictiomary of Superstitions, p. 395. 